\title{
A case describing patients with COVID-19 that secondarily transmitted
}

\author{
Yanan Zhang ${ }^{1}$, Xia Cao ${ }^{1}$, Juan $\mathrm{Ma}^{2}$, Li Zhu ${ }^{3}$, Juan Chen ${ }^{1}$ \\ ${ }^{1}$ Department of Respiratory and Critical Care Medicine, General Hospital of Ningxia Medical University, Yinchuan, China; ${ }^{2}$ Department of \\ Infectious Diseases, General Hospital of Ningxia Medical University, Yinchuan, China; ${ }^{3}$ Department of Radiology, General Hospital of Ningxia \\ Medical University, Yinchuan, China \\ Contributions: (I) Conception and design: J Chen, Y Zhang; (II) Administrative support: J Chen, L Zhu; (III) Provision of study materials or patients: \\ J Ma, J Chen; (IV) Collection and assembly of data: Y Zhang, X Cao; (V) Data analysis and interpretation: Y Zhang, L Zhu; (VI) Manuscript writing: \\ All authors; (VII) Final approval of manuscript: All authors. \\ Correspondence to: Juan Chen. Department of Respiratory and Critical Care Medicine, General Hospital of Ningxia Medical University, 804 Shengli \\ Street, Xingqing, Yinchuan 750004, China. Email: chenjuan7419@163.com.
}

Background The recent emergence of coronavirus disease 2019 (COVID-19) is a major global health threat. Monitoring viral transmission and disease characteristics as the disease spreads globally is vital. This study aimed to describe the clinical characteristics and source of infection in patients with secondary transmission of COVID-19 outside the outbreak area.

Methods: The epidemiological, demographic, clinical, laboratory, radiological, and treatment data of five patients with laboratory-confirmed COVID-19 who were treated in the General Hospital of Ningxia Medical University (Ningxia, China) from 1 January 2020 to 1 March 2020 were presented. The final followup evaluation was performed on 12 March 2020.

Results: The five participants included two couples and a young woman, none of whom had visited Hubei. It was likely that four of the participants had been infected by exposure to asymptomatic visitors from Wuhan. The other participant lived in a densely-populated community with potential COVID-19 cases. A variety of symptoms were presented by four participants, including cough, fevers, sputum, breathlessness, chest pain, fatigue, sore limbs, sore throats, headaches, and rhinorrhea. A severe infection, with dyspnea and decreased oxygen saturation, was experienced by one participant who had a history of chronic bronchitis. A single participant was asymptomatic, but had ground-glass opacities (GGOs) on chest imaging. Another two participants also displayed GGOs. Lymphopenia was noted in three participants. During the follow-up period, all participants were cured and discharged to their homes.

Conclusions: This study included patients who had acquired infections of COVID-19 through local transmission. These findings will provide a better understanding of secondary transmission of COVID-19.

Keywords! Coronavirus disease 2019 (COVID-19); secondary outbreak; clustering occurrence; China

Submitted Jun 10, 2021. Accepted for publication Aug 10, 2021.

doi: 10.21037/apm-21-1757

View this article at: https://dx.doi.org/10.21037/apm-21-1757

\section{Introduction}

An outbreak of respiratory disease caused by a novel coronavirus was first reported in December 2019. The coronavirus was designated as severe acute respiratory syndrome coronavirus 2 (SARS-CoV-2), while the resulting disease was officially termed coronavirus disease
2019 (COVID-19) by the World Health Organization (WHO) (1). The epidemic spread rapidly around the globe. The WHO declared COVID-19 a pandemic on March 12, 2020 (2). As of July 1, 2020, >10 million people in over 188 countries had been infected with SARS-CoV-2 (3).

Until recently, most human coronavirus infections caused 
mild symptoms; however, in the past several decades two novel coronavirus infections have caused severe symptoms in select patients. In 2003, the SARS-CoV infection was shown to cause severe acute respiratory syndrome (SARS) with a mortality rate of $9.6 \%$, and in 2012 MERS-CoV infection caused Middle East respiratory syndrome (MERS) with a mortality rate of $34.4 \%(4,5)$. Like SARS-CoV and MERS-CoV, SARS-CoV-2 belongs to the B lineage of beta-coronaviruses $(6,7)$. These coronaviruses are widely distributed in humans and other mammals (8). The ability to infect multiple host species suggests that these viruses are a common cause of zoonotic infections in humans. The genome of SARS-CoV has a $96 \%$ sequence match to a bat coronavirus, $79 \%$ with SARS-CoV, and 50\% to MERS$\mathrm{CoV}(7,9)$. Thus, the source for COVID-19 was likely a wild animal; the primary reservoir is possibly from bats, but there may be intermediate hosts.

The exponential rise in the number of infections and the increase in population movements at the end of the year are signs that COVID-19 is spreading from person to person (10). Indeed, the ongoing pandemic has affected people in virtually all countries, making it clear that personto-person transmission is involved $(5,11)$ and controlling viral spread difficult (12). Such as the outbreak on the Diamond Princess cruise ship, showed the potential for rapid increases in infection within confined spaces (13).

The prevalence of the COVID-19 and the source of the infection are still uncertain. Most studies since the outbreak have focused on providing data on the risk of infection and clinical symptoms in different patient groups. As reported in Zhang et al., the risk of COVID-19 infection in cancer patients was explored (14). However, few studies have been reported on patients with most of the illnesses caused by secondary transmission outside the outbreak area. Whether COVID-19 differs between patients with direct infection and those with the secondary transmission of infection, this information plays an important role in the prevention and treatment (15). In addition, secondary transmission studies will make it possible to observe the potential route of COVID-19 transmission and whether the disease evolves with transmission. Therefore, this study reports cases of secondary transmission of COVID-19 infection in Ningxia, China, thus assisting in the treatment and prevention of COVID-19. We present the following article in accordance with the MDAR reporting checklist (available at https:// dx.doi.org/10.21037/apm-21-1757).

\section{Methods}

\section{Participants}

This was a retrospective case series of patients with confirmed COVID-19 that was considered to be due to secondary transmission and who were treated in the General Hospital of Ningxia Medical University from 26 January 2020 to 1 March 2020. The COVID-19 diagnosis was made according to the WHO interim guidelines (16) and the COVID-19 diagnosis and treatment plan (trial version 7) developed by the National Health Committee in China (http://www.nhc.gov.cn/). A possible case was defined as an individual presenting with acute respiratory symptoms after visiting the Hubei province or at risk of exposure from a patient with a confirmed diagnosis in the 14 days before symptom onset. A confirmed case was defined as a possible case with a positive COVID real-time reverse-transcription polymerase chain reaction (RT-PCR) test from nasopharyngeal swabs performed by an accredited laboratory. A case of secondary transmission was defined as a patient in whom the infection was acquired due to subsequent local transmission without travel to Wuhan.

All procedures performed in this study involving human participants were in accordance with the Declaration of Helsinki (as revised in 2013). The study was approved by the Institutional Review Board of The General Hospital of Ningxia Medical University (No.: 2020-496). Individual consent for this retrospective analysis was waived.

\section{Laboratory tests}

Throat swab samples collected from suspected cases were tested using RT-PCR for COVID-19 RNA. The detection reagents were obtained from Shanghai Jie Nuo Biotechnology Co., Ltd. (Shanghai, China) and Guangzhou Da An Biotechnology Co., Ltd. (Guangzhou, China). The samples were sent to the local Center for Disease Control and Prevention (CDC) for confirmation.

Blood samples were tested for the presence of immunoglobulin $M$ (IgM) and immunoglobulin G ( $\operatorname{IgG}$ ) raised against other respiratory pathogenic targets, including 12 respiratory viruses [adenovirus, respiratory syncytial virus, influenza A viruses ( $\mathrm{H} 1$ and $\mathrm{H} 3)$, influenza B virus, parainfluenza viruses (types 1-3), herpes simplex virus, cytomegalovirus, toxoplasma (toxoplasma is a protozoan), and rubella virus] and 3 bacteria (Chlamydophila 


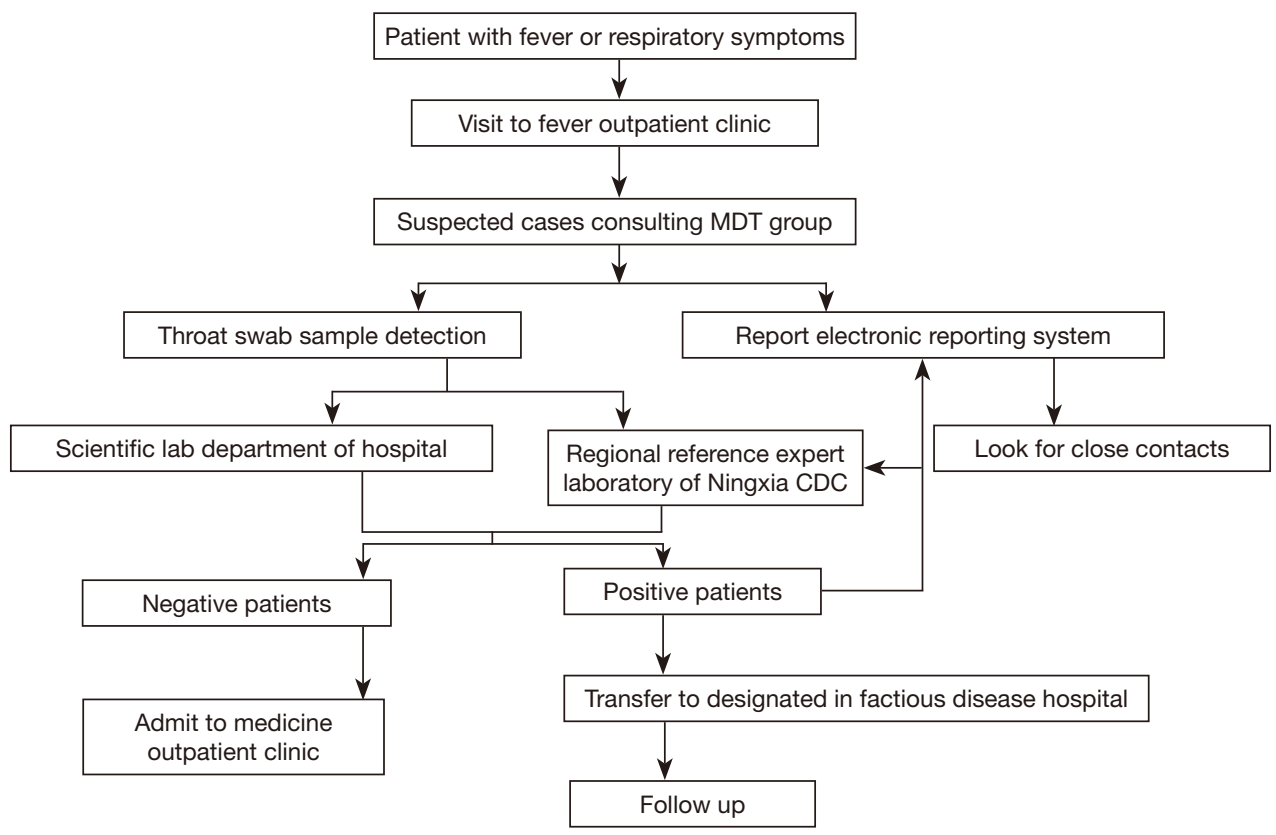

Figure 1 Protocol for COVID-19 management. COVID-19, coronavirus disease 2019; MDT, Multi-disciplinary Diagnosis and Treatment; CDC, Centers for Disease Control and Prevention.

pneumoniae, Mycoplasma pneumoniae, and Legionella pneumophila). The detection reagents were obtained from Vircell Microbiologist S.L. (Granada, Andalusia, Spain) and DiaSorin S.p.A (Saluggia, Vercell, Italy).

\section{Clinical management of outpatient cases}

The protocol for COVID-19 management in the General Hospital of Ningxia Medical University included early detection and nasopharyngeal swabbing of all suspected cases. The clinical management of outpatients was based on the emergency response plan and established surveillance protocol (Figure 1).

\section{Statistical analysis}

Demographic data, medical histories, epidemiological histories, symptoms, signs, laboratory findings, and chest computed tomographic (CT) findings were collected. The day of disease onset was defined as the day on which the first symptom was noticed (16). The severity of symptoms was categorized as mild, common, severe, or critical according to Chinese guidelines (trial version 7; http://www.nhc.gov.cn/). Mild cases included patients with no evidence of pneumonia or mild pneumonia. Common cases presented with fevers and respiratory symptoms, and had radiographic evidence of pneumonia. Severe cases were characterized by dyspnea, respiratory rate $\geq 30 / \mathrm{min}$, blood oxygen saturation $\leq 93 \%$, partial pressure of arterial oxygen to fractional inspired oxygen concentration ratio $\left(\mathrm{PaO}_{2} / \mathrm{FiO}_{2}\right)<300$, and/or lung infiltrates in $>50 \%$ of the lung fields within $24-48 \mathrm{~h}$. Critical cases exhibited respiratory failure, septic shock, and/or multiple organ dysfunction/failure.

\section{Results}

There were five laboratory-confirmed cases enrolled in this study. All participants were local residents and designated as cases 1-5 according to their order of presentation to the hospital. Table 1 summarizes the clinical features and laboratory findings of the five COVID-19 patients.

\section{Cases 1 and 2}

Cases 1 and 2 were a couple who had been running a restaurant for 10 years. They had no history of visiting Wuhan or contact with wild animals. They came into contact with a person in the incubation period from Wuhan in their restaurant 6 days before their onset of symptoms.

Case 1 (wife) was a 47-year-old female who sought 
Table 1 Clinical features and laboratory findings of the assessed COVID-19 patients

\begin{tabular}{|c|c|c|c|c|c|}
\hline Variables & Case 1 & Case 2 & Case 3 & Case 4 & Case 5 \\
\hline Age (years) & 47 & 53 & 50 & 51 & 28 \\
\hline Sex & Female & Male & Female & Male & Female \\
\hline BMI $\left(\mathrm{kg} / \mathrm{m}^{2}\right)$ & 22.86 & 31.14 & 19.10 & 24.22 & 21.34 \\
\hline Exposure history & \multicolumn{2}{|c|}{ Occupational environment } & \multicolumn{2}{|c|}{ Close contact with an imported case } & Dense community \\
\hline Chronic medical illness & Chronic bronchitis & Hypertension, obesity & None & None & None \\
\hline $\begin{array}{l}\text { Interval between symptom onset and } \\
\text { hospital admission (days) }\end{array}$ & 4 & No symptoms & 1 & 1 & 2 \\
\hline Presenting symptoms & $\begin{array}{l}\text { Cough, sputum, } \\
\text { breathless, and } \\
\text { chest pain }\end{array}$ & No symptoms & $\begin{array}{l}\text { Fever, cough, } \\
\text { fatigue and sore } \\
\text { limbs }\end{array}$ & $\begin{array}{l}\text { Fever and sore } \\
\text { throat }\end{array}$ & $\begin{array}{l}\text { Fever, headache, } \\
\text { rhinorrhea and } \\
\text { fatigue }\end{array}$ \\
\hline Body temperature $\left({ }^{\circ} \mathrm{C}\right)$ & 38 & 36 & 39.2 & 37.6 & 38.5 \\
\hline Respiratory rate (/min) & 33 & 20 & 21 & 19 & 20 \\
\hline Oximetry saturation (\%) & 89 & 97 & 94 & 96 & 95 \\
\hline Chest CT findings & $\begin{array}{l}\text { Mixed GGO and } \\
\text { consolidation }\end{array}$ & Unilateral GGO & Bilateral GGO & Normal & Normal \\
\hline \multicolumn{6}{|l|}{ Blood, routine } \\
\hline $\begin{array}{l}\text { White blood cell count (normal } \\
\text { range } 3.5-9.5 \times 10^{9} / \mathrm{L} \text { ) }\end{array}$ & 4.21 & 4.19 & $3.46(\downarrow)$ & 9.54 & $3.26(\downarrow)$ \\
\hline PLT (normal range 115-150 g/L) & 195 & 202 & 135 & 249 & 204 \\
\hline \multicolumn{6}{|l|}{ Blood gas analysis } \\
\hline $\mathrm{pH}$ (normal range 7.35-7.45) & 7.485 & 7.396 & 7.39 & 7.40 & 7.37 \\
\hline $\mathrm{PCO}_{2}$ (normal range $35-45 \mathrm{mmHg}$ ) & 34.5 & 40.4 & 44.1 & 36.8 & 42 \\
\hline $\mathrm{PO}_{2}$ (normal range $70-100 \mathrm{mmHg}$ ) & 80.8 (4 L/min) & 76.7 & 75.1 & 80.5 & 79 \\
\hline CRP (normal range 0-5 mg/L) & 71.6 & 5.0 & 48.4 & 4.0 & 4.7 \\
\hline PCT (normal range $<0.5$ ng/mL) & $0.5 \leq \mathrm{PCT}<2$ & Negative & Negative & Negative & Negative \\
\hline $\begin{array}{l}\text { Nine respiratory pathogens and eight } \\
\text { viruses tested }\end{array}$ & Negative & Negative & Negative & Negative & Negative \\
\hline Transfer time & January 29 & January 29 & January 31 & January 31 & February 10 \\
\hline Discharge time & February 20 & February 18 & February 12 & February 14 & February 18 \\
\hline
\end{tabular}

COVID-19, coronavirus disease 2019; BMI, body mass index; CT, computed tomography; HGB, hemoglobin; $\mathrm{PLT}_{\text {, platelets; } \mathrm{PCO}}$, partial pressure of carbon dioxide; $\mathrm{PO}_{2}$, partial pressure of oxygen; $\mathrm{CRP}, \mathrm{C}$-reactive protein; $\mathrm{PCT}$, procalcitonin. 
evaluation at a fever outpatient clinic with fevers, cough, sputum, breathlessness, and chest pain of 4 days duration on 25 January. She had also experienced a chronic cough over the past 3 years with a history of chronic bronchitis. Increased C-reactive protein (CRP) and procalcitonin (PCT) levels (inflammation indicators) and lymphopenia were recorded. Chest CT images showed multiple groundglass opacities (GGOs) and parenchymal consolidation in the lungs bilaterally (Figure 1). The creatine kinase (CK) and lactate dehydrogenase (LDH) enzyme indices were increased (358.7 U/L and 1,039 U/L, respectively). She was diagnosed with severe COVID-19 based on her shortness of breath, respiratory rate $>30 / \mathrm{min}$, and peripheral capillary oxygen saturation $\left(\mathrm{SpO}_{2}\right)<93 \%$, as specified in the Chinese guidelines. Case 2 (husband) was a 53-year-old male with hypertension and obesity and was confirmed with the same disease 2 days later (January 27). Although he was asymptomatic, focal GGOs were noted on CT (Figure 2).

Cases 1 and 2 were transferred to the designated hospital on 29 January after COVID-19 had been diagnosed. Case 1 received aerosolized recombinant human interferon $\alpha-2 \mathrm{a}$ (5 million U bid), oral arbidol ( $0.2 \mathrm{mg}$ tid), and moxifloxacin (400 mg qd) and high-flow oxygen inhalation for 7 days. Her condition improved and she was discharged to home on 20 February. Case 2 was classified as a common case and received oral traditional Chinese medicine (Qingfei Paidu decoction) and was discharged to home on 18 February.

\section{Cases 3 and 4}

Cases 3 and 4 were also a couple, both of whom sought evaluation at the hospital on 29 January. Their daughter, an undergraduate student living in Wuhan, had flown back to Yinchuan on 22 January for a winter break.

Case 3 (wife) was a 50-year-old female who developed fevers and fatigue 7 days after the arrival of her daughter. Blood testing showed lymphopenia and a CT scan revealed multiple GGOs in the lungs bilaterally (Figure 2). Case 4 (husband) was a 51-year-old male who presented with fevers and lymphopenia, but the CT findings were normal (Figure 1). Cases 3 and 4 were transferred to the designated hospital on 31 January. Case 3 was diagnosed as a common case and received oral arbidol (0.2 $\mathrm{mg}$ tid) and traditional Chinese medicine (Qingfei Paidu decoction) and was discharged to home on 12 February, while case 4 had a mild case and received oral traditional Chinese medicine only (Qingfei Paidu decoction) and was discharged to home on 14 February.
The daughter was asymptomatic and was admitted to another regional reference hospital for isolation. She tested positive for COVID-19 the day after placement in isolation.

\section{Case 5}

Case 5 was diagnosed with a mild case. She was a 28 -year-old lactating mother of an 11-month-old baby. No detailed information was available about the circumstances of her exposure to COVID-19. She lived in a denselypopulated community and might have shared an elevator with an infected person. Case 5 presented with fevers and lymphopenia, but the CT findings were normal (Figure 2). Her husband and daughter were not affected. She sought evaluation at a fever clinic on 8 February and was transferred to the designated hospital on 10 February. She received oral arbidol $(0.2 \mathrm{mg}$ tid) and traditional Chinese medicine (Qingfei Paidu decoction) and was discharged to home on 18 February.

All of the confirmed cases were immediately transferred to the infectious disease hospital in Ningxia for isolation and management. During the follow-up period, all participants were cured and discharged to home. The requirements for discharge included two negative nucleic acid tests at $24 \mathrm{~h}$ intervals.

\section{Discussion}

The current pandemic outbreak of COVID-19 began in December 2019, and was soon detected worldwide (1). Most current studies have focused on providing data on the risk of infection and clinical symptoms in different patient groups. For example, the study by Xie et al. focused on detecting clinical features in patients with a confirmed COVID-19 diagnosis (17). In addition, there are studies on pediatric patients with COVID-19 (18). The major problem facing most areas outside the outbreak areas is secondary transmission. However, there has been little research on secondary transmission. We reported a series of five laboratory-confirmed COVID-19 patients who were infected via subsequent local transmission in Ningxia (western part of China). These participants were all successfully treated and discharged during the follow-up period.

All participants showed characteristics of a clustered onset. This finding supported the information published in larger studies. An analysis of the first 425 confirmed cases in Wuhan provided evidence that human-to-human 
A
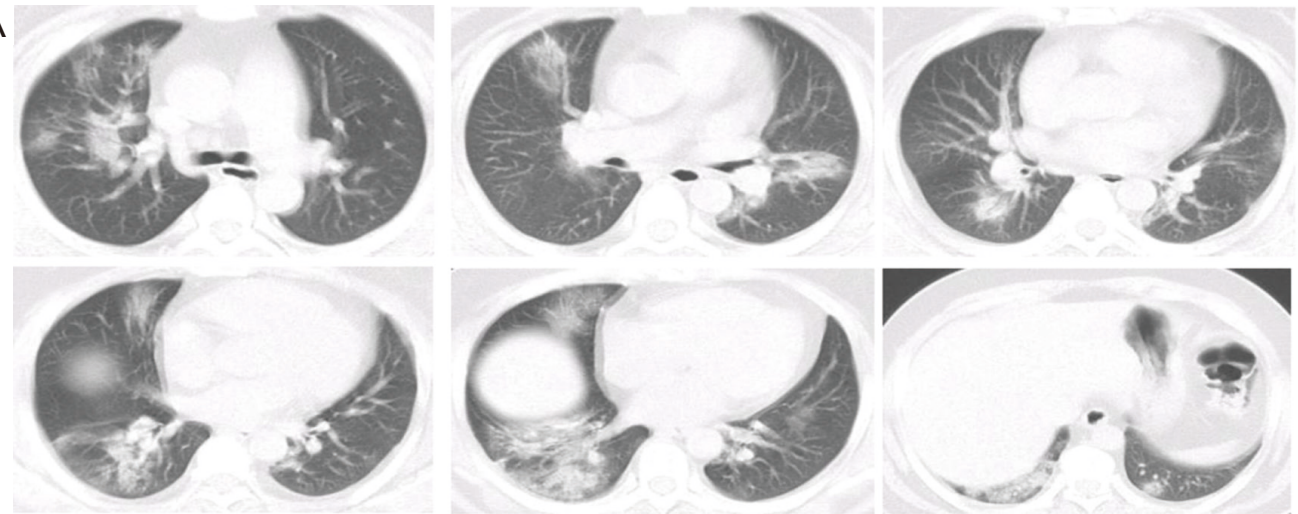

B r
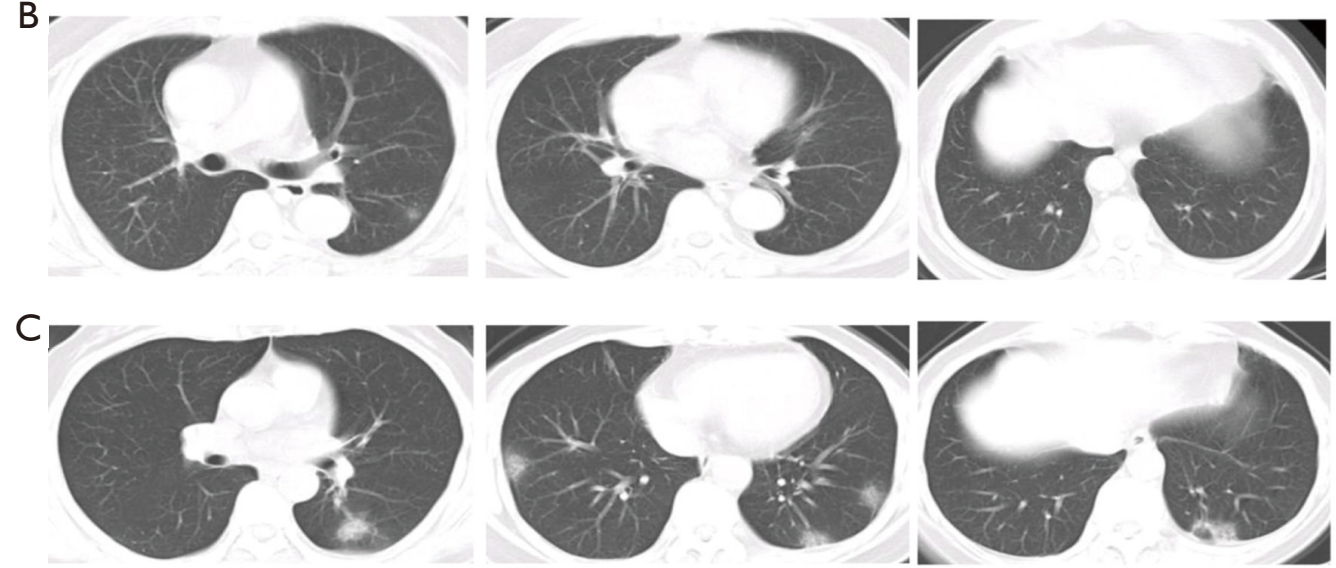

D
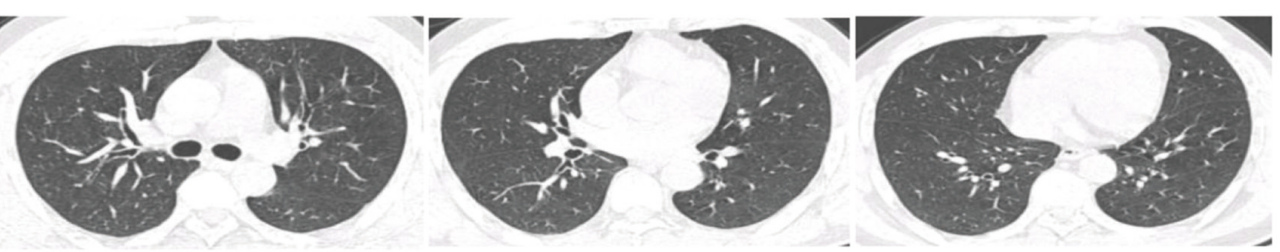

\section{E}
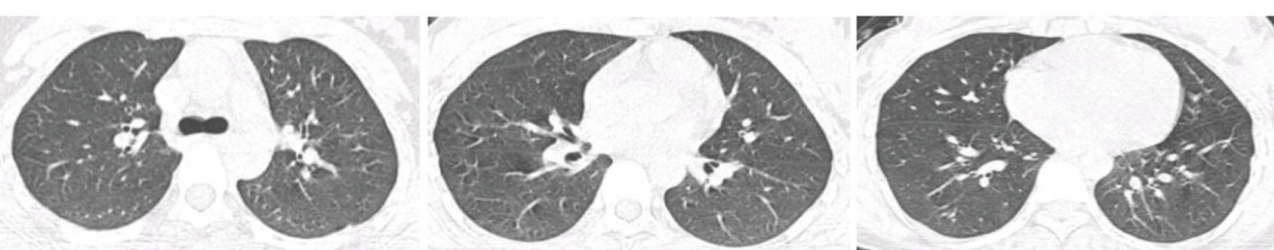

Figure 2 Chest CT images of the cases series of COVID-19 patients. (A) CT showing bilateral GGOs and consolidation opacities (case 1), (B) unilateral GGOs (case 2), (C) bilateral GGOs (case 3), (D,E) normal findings (cases 4 and 5). CT, computed tomography; COVID-19, coronavirus disease 2019; GGOs, ground-glass opacities.

transmission had occurred among close contacts since midDecember 2019 (19). The basic reproductive number (R0) was estimated to be 2.2 [95\% confidence interval (CI): 1.4 to 3.9 ] with a mean serial interval (SI) of $7.5 \mathrm{~d}$, indicating that each patient spread infection to 2.2 other individuals compared to a mean R0 range from 2.2 to 3.58 using the SIs of two other well-known coronavirus-related diseases (MERS and SARS) (20). When COVID-19 cases are in 
close contact, such as onboard the Diamond Princess cruise ship, the mean R0 in the confined setting reached values as high as 11 (13). Part of the reason for the rapid increase in the number of COVID-19 cases may be the result of asymptomatic presentation in some virus carriers (21). This finding was supported in this case series because in only one case (case 5) could the source of infection not be ascertained, while in the other four cases the source of infection was from a patient in their incubation period (cases 1 and 2) or before symptoms arose (cases 3 and 4). These transmission characteristics justify the currently observed global spread and have important implications for disease control and management.

Respiratory droplets from close personal contact and contact with aerosol-contaminated surfaces are thought to be the main routes of COVID-19 transmission $(22,23)$; however, a previous study also suggested the possibility of aerosol transmission over a larger distance (24). Indeed, the fecal-oral route of transmission is also possible (25). In the current study the only patient without an identified direct source of infection was the 28-year-old woman (case 5) living in a densely-populated community. She shared an elevator and may have come in contact with COVID-19 on surfaces within the elevator. Despite her infection, her baby and husband remained healthy. While vertical transmission between mothers and infants is another possible route of infection, based on a study reporting two cases of neonates with positive COVID-19 (26), it remains uncertain whether breastfeeding could transmit the virus. In this case, the participant was a lactating mother whose baby remained unaffected. This result is important and can be followed up with studies, which could be a potential route of transmission of COVID-19 and a potential means of prevention.

Disease onset in both couples included in this case series coincided with the peak of the Wuhan outbreak. A couple (cases 3 and 4) had a close contact with a traveler (their daughter returning home from Wuhan) who was asymptomatic at the time. Although the female participant presented with multiple GGOs, her husband had upper respiratory tract infection symptoms but normal CT findings. In the second couple, case 1 had GGOs and parenchymal consolidation in the lungs bilaterally, while her husband was asymptomatic with unilateral GGOs on CT scan. It has been shown that most COVID-19 cases have similar features on CT images, typically including GGOs or mixed GGOs and consolidation pulmonary opacities (27). It is characteristic of COVID-19 to have a peripheral distribution with bilateral, multifocal lower lung involvement $(28,29)$. Notably, CT findings may precede the actual symptoms. Therefore, CT features play a crucial role in the early diagnosis of suspected cases, especially for COVID-19-negative RT-PCR cases with a typical exposure history (30). Repeated swab testing and isolation management should be considered in such cases.

Case 1, who presented with dyspnea and decreased oxygen saturation, and also had an underlying disease (chronic bronchitis), was the only severe COVID-19 case in this study. Her CT showed consolidation lesions in both lungs and serum PCT level was increased, suggesting mixed infections with viruses and bacteria. Analysis of the initial 138 confirmed cases in Wuhan revealed that severe cases were associated with older age and underlying diseases (31). The potential risk factors of older age, high sequential organ failure assessment (SOFA) score, and d-dimer $>1 \mu \mathrm{g} / \mathrm{L}$ could help clinicians identify patients with poor prognosis at an early stage (32). The Chinese CDC has reviewed 72,314 patient records extracted from the China's Infectious Disease Information System and updated through 11 February 2020 (33). Most cases were classified as mild (81\%), severe (14\%), and critical (5\%). Although the overall case-fatality rate (CFR) was $2.3 \%$, cases aged $70-79$ and $\geq 80$ years of age had CFRs of $8.0 \%$ and $14.8 \%$, respectively. No deaths were reported among the mild and severe cases, while the CFR was $49.0 \%$ among critical cases. The preliminary data from other countries have reported similar results (34-36). It is important that the COVID-19 pandemic continues to be monitored.

Basic laboratory studies suggest that the human cell receptor for SARS-CoV-2, the COVID-19 agent, may be the angiotensin-converting enzyme 2 (ACE2) receptor and similar to that of SARS-CoV (6). Both SARS-CoV-2 and SARS-CoV have very similar 3-D structures of the glycosylated spike protein, which is considered to have an affinity for ACE2 (37); however, COVID-19 binds ACE2 with a higher binding affinity than SARS-CoV (>10-20-fold) $(38,39)$. This finding may explain why COVID-19 is more contagious than SARS. Additionally, ACE2 distributes across distinct cell types in many different organs, thus coreceptors or other cell surface accessory proteins are likely to play a role in determining tissue susceptibility (40). Research based on single-cell RNA sequencing datasets derived from major human physiologic systems, including the respiratory, cardiovascular, digestive, and urinary systems, has generated a risk map for different human organs vulnerable to COVID-19 (41). Based on this finding, 
pulmonary alveolar type II (AT2) and lung epithelial cells should be considered at highest risk. In addition, $>1 \%$ of some cell types from the respiratory tract, kidneys, esophagus, bladder, ileum, and heart also express ACE2. Therefore, these organs are potentially at high risk for COVID-19 infection. This may explain the non-respiratory symptoms observed in COVID-19 patients that have also been described in SARS $(42,43)$.

The limitations of the current study should be mentioned. The sample size of this study was small. Only five patients were included. Although this study has the limitation of small sample size, it can still provide some prevention and treatment suggestions for other areas outside the outbreak area. Firstly, the cases diagnosed in this study were all relatively mild compared to patients in the outbreak areas. Therefore, many areas with inadequate medical facilities do not need to be overly alarmed when infected patients are found, but only need to do the relevant isolation work and treat the patients as soon as possible. The treatment plan refers to the "Treatment Plan for Novel Coronavirus Pneumonia" jointly issued by the General Office of the National Health Commission of China and the Office of the Chinese Traditional Medicine Administration. In it, there are corresponding treatment protocols for different types of patients. Secondly, elderly patients who have a history of the disease themselves have a greater chance of developing into seriously ill patients, so careful screening of the patient's medical history is needed to facilitate treatment. In addition, because some patients do not show any symptoms during the incubation period, people entering from more severely affected areas need to be screened more carefully, and the isolation period can be extended if necessary. Finally, public facilities in densely populated areas need to be disinfected more frequently. According to the above preventive measures, secondary transmission of COVID-19 can be effectively reduced.

\section{Conclusions}

In summary, we have described the epidemiological and clinical features of patients secondarily infected with COVID-19 in the Ningxia region of China. As of 12 March these five people were the first confirmed cluster cases of COVID-19 in Ningxia, and were followed for 14 days after isolation. No further transmission events to tertiary cases have been detected thus far, despite active follow-up.

\section{Acknowledgments}

Funding: This study was supported by the Natural Science Foundation of Ningxia Hui Autonomous: study on the pathogenesis of novel coronavirus pneumonia (No. 2020AAC02001), and study on the mechanism of Nrf2 in accelerated aging in chronic obstructive pulmonary disease (No. 2019AAC03183); Key Research and Development Program of Ningxia Hui Autonomous: HRCT-based improvement in prevention and control of novel coronavirus pneumonia 2019-nCoV and prognostic follow-up (No. 2020BEG03055); First-Class Discipline Construction Founded Project of Ningxia Medical University and the School of Clinical Medicine (No. NXYLXK2017A05).

\section{Footnote}

Reporting Checklist: The authors have completed the MDAR reporting checklist. Available at https://dx.doi. org/10.21037/apm-21-1757

Data Sharing Statement: Available at https://dx.doi. org/10.21037/apm-21-1757

Conflicts of Interest: All authors have completed the ICMJE uniform disclosure form (available at https://dx.doi. org/10.21037/apm-21-1757). The authors have no conflicts of interest to declare.

Ethical Statement: The authors are accountable for all aspects of the work in ensuring that questions related to the accuracy or integrity of any part of the work are appropriately investigated and resolved. All procedures performed in this study involving human participants were in accordance with the Declaration of Helsinki (as revised in 2013). The study was approved by the Institutional Review Board of The General Hospital of Ningxia Medical University (No.: 2020-496). Individual consent for this retrospective analysis was waived.

Open Access Statement: This is an Open Access article distributed in accordance with the Creative Commons Attribution-NonCommercial-NoDerivs 4.0 International License (CC BY-NC-ND 4.0), which permits the noncommercial replication and distribution of the article with the strict proviso that no changes or edits are made and the 
original work is properly cited (including links to both the formal publication through the relevant DOI and the license). See: https://creativecommons.org/licenses/by-nc-nd/4.0/.

\section{References}

1. Sohrabi C, Alsafi Z, O'Neill N, et al. World Health Organization declares global emergency: a review of the 2019 novel coronavirus (COVID-19). Int J Surg 2020;76:71-6.

2. Purkayastha S, Bhattacharyya R, Bhaduri R, et al. A comparison of five epidemiological models for transmission of SARS-CoV-2 in India. BMC Infect Dis 2021;21:533.

3. Michael-Kordatou I, Karaolia P, Fatta-Kassinos D. Sewage analysis as a tool for the COVID-19 pandemic response and management: the urgent need for optimised protocols for SARS-CoV-2 detection and quantification. J Environ Chem Eng 2020;8:104306.

4. Velavan TP, Meyer CG. The COVID-19 epidemic. Trop Med Int Health 2020;25:278-80.

5. Chan JF, Yuan S, Kok KH, et al. A familial cluster of pneumonia associated with the 2019 novel coronavirus indicating person-to-person transmission: a study of a family cluster. Lancet 2020;395:514-23.

6. Zhou P, Yang XL, Wang XG, et al. A pneumonia outbreak associated with a new coronavirus of probable bat origin. Nature 2020;579:270-3.

7. Zhu N, Zhang D, Wang W, et al. A novel coronavirus from patients with pneumonia in China, 2019. N Engl J Med 2020;382:727-33.

8. Fung TS, Liu DX. Human coronavirus: host-pathogen interaction. Annu Rev Microbiol 2019;73:529-57.

9. Phan T. Novel coronavirus: from discovery to clinical diagnostics. Infect Genet Evol 2020;79:104211.

10. Wang L, Gao YH, Lou LL, et al. The clinical dynamics of 18 cases of COVID-19 outside of Wuhan, China. Eur Respir J 2020;55:2000398.

11. Cai J, Sun W, Huang J, et al. Indirect virus transmission in cluster of COVID-19 cases, Wenzhou, China, 2020. Emerg Infect Dis 2020;26:1343-5.

12. Maier BF, Brockmann D. Effective containment explains subexponential growth in recent confirmed COVID-19 cases in China. Science 2020;368:742-6.

13. Mizumoto K, Chowell G. Transmission potential of the novel coronavirus (COVID-19) onboard the diamond Princess Cruises Ship, 2020. Infect Dis Model 2020;5:264-70.

14. Zhang H, Wang L, Chen Y, et al. Outcomes of novel coronavirus disease 2019 (COVID-19) infection in 107 patients with cancer from Wuhan, China. Cancer 2020;126:4023-31.

15. Yang W, Cao Q, Qin L, et al. Clinical characteristics and imaging manifestations of the 2019 novel coronavirus disease (COVID-19): a multi-center study in Wenzhou city, Zhejiang, China. J Infect 2020;80:388-93.

16. World Health Organization. Clinical management of COVID-19: interim guidance, 27 May 2020. Geneva: World Health Organization, 2020.

17. Xie J, Ding C, Li J, et al. Characteristics of patients with coronavirus disease (COVID-19) confirmed using an IgMIgG antibody test. J Med Virol 2020;92:2004-10.

18. Cui $X$, Zhao Z, Zhang T, et al. A systematic review and meta-analysis of children with coronavirus disease 2019 (COVID-19). J Med Virol 2021;93:1057-69.

19. Li Q, Guan X, Wu P, et al. Early transmission dynamics in Wuhan, China, of novel coronavirus-infected pneumonia. N Engl J Med 2020;382:1199-207.

20. Zhao S, Lin Q, Ran J, et al. Preliminary estimation of the basic reproduction number of novel coronavirus (2019-nCoV) in China, from 2019 to 2020: a data-driven analysis in the early phase of the outbreak. Int J Infect Dis 2020;92:214-7.

21. Dawood AA. Mutated COVID-19 may foretell a great risk for mankind in the future. New Microbes New Infect 2020;35:100673.

22. Guo YR, Cao QD, Hong ZS, et al. The origin, transmission and clinical therapies on coronavirus disease 2019 (COVID-19) outbreak - an update on the status. Mil Med Res 2020;7:11.

23. Fathizadeh H, Maroufi P, Momen-Heravi M, et al. Protection and disinfection policies against SARS-CoV-2 (COVID-19). Infez Med 2020;28:185-91.

24. Wax RS, Christian MD. Practical recommendations for critical care and anesthesiology teams caring for novel coronavirus (2019-nCoV) patients. Can J Anaesth 2020;67:568-76.

25. Zhang W, Du RH, Li B, et al. Molecular and serological investigation of 2019-nCoV infected patients: implication of multiple shedding routes. Emerg Microbes Infect 2020;9:386-9.

26. Wang L, Shi Y, Xiao T, et al. Chinese expert consensus on the perinatal and neonatal management for the prevention and control of the 2019 novel coronavirus infection (First edition). Ann Transl Med 2020;8:47.

27. Dai WC, Zhang HW, Yu J, et al. CT imaging and differential diagnosis of COVID-19. Can Assoc Radiol J 
2020;71:195-200.

28. Bai HX, Hsieh B, Xiong Z, et al. Performance of radiologists in differentiating COVID-19 from nonCOVID-19 viral pneumonia at chest CT. Radiology 2020;296:E46-54.

29. Kanne JP. Chest CT findings in 2019 novel coronavirus (2019-nCoV) infections from Wuhan, China: key points for the radiologist. Radiology 2020;295:16-7.

30. Xie X, Zhong Z, Zhao W, et al. Chest CT for typical coronavirus disease 2019 (COVID-19) pneumonia: relationship to negative RT-PCR testing. Radiology 2020;296:E41-5.

31. Wang D, Hu B, Hu C, et al. Clinical characteristics of 138 hospitalized patients with 2019 novel coronavirus-infected pneumonia in Wuhan, China. JAMA 2020;323:1061-9. Erratum in: JAMA 2021;325:1113.

32. Zhou F, Yu T, Du R, et al. Clinical course and risk factors for mortality of adult inpatients with COVID-19 in Wuhan, China: a retrospective cohort study. Lancet 2020;395:1054-62.

33. Wu Z, McGoogan JM. Characteristics of and important lessons from the coronavirus disease 2019 (COVID-19) outbreak in China: summary of a report of 72314 cases from the Chinese Center for Disease Control and Prevention. JAMA 2020;323:1239-42.

34. CDC COVID-19 Response Team. Severe outcomes among patients with coronavirus disease 2019 (COVID-19) - United States, February 12-March 16, 2020. MMWR Morb Mortal Wkly Rep 2020;69:343-6.

35. Korean Society of Infectious Diseases and Korea Centers for Disease Control and Prevention. Analysis on 54 mortality cases of coronavirus disease 2019 in the Republic of Korea from January 19 to March 10, 2020. J Korean

Cite this article as: Zhang Y, Cao X, Ma J, Zhu L, Chen J. A case describing patients with COVID-19 that secondarily transmitted. Ann Palliat Med 2021;10(8):8972-8981. doi: 10.21037/ apm-21-1757
Med Sci 2020;35:e132.

36. Porcheddu R, Serra C, Kelvin D, et al. Similarity in case fatality rates (CFR) of COVID-19/SARS-COV-2 in Italy and China. J Infect Dev Ctries 2020;14:125-8.

37. Wrapp D, Wang N, Corbett KS, et al. Cryo-EM structure of the 2019-nCoV spike in the prefusion conformation. Science 2020;367:1260-3.

38. Ortega JT, Serrano ML, Pujol FH, et al. Role of changes in SARS-CoV-2 spike protein in the interaction with the human ACE2 receptor: an in silico analysis. EXCLI J 2020;19:410-7.

39. Liu Z, Xiao X, Wei X, et al. Composition and divergence of coronavirus spike proteins and host ACE2 receptors predict potential intermediate hosts of SARS-CoV-2. J Med Virol 2020;92:595-601.

40. Qi F, Qian S, Zhang S, et al. Single cell RNA sequencing of 13 human tissues identify cell types and receptors of human coronaviruses. Biochem Biophys Res Commun 2020;526:135-40.

41. Zou X, Chen K, Zou J, et al. Single-cell RNA-seq data analysis on the receptor ACE2 expression reveals the potential risk of different human organs vulnerable to 2019-nCoV infection. Front Med 2020;14:185-92.

42. Ozma MA, Maroufi P, Khodadadi E, et al. Clinical manifestation, diagnosis, prevention and control of SARSCoV-2 (COVID-19) during the outbreak period. Infez Med 2020;28:153-65.

43. Xu J, Zhao S, Teng T, et al. Systematic comparison of two animal-to-human transmitted human coronaviruses: SARS-CoV-2 and SARS-CoV. Viruses 2020;12:244.

(English Language Editor: J. Jones) 